\title{
DEVELOPMENT OF A METHOD FOR DIAGNOSING INJECTORS OF DIESEL ENGINES
}

\author{
Ildar Gabitov*, Andrei Negovora, Shamil Nigmatullin, Arseny Kozeev, Mahmut Razyapov
}

Department of Automobiles and Machine-Tractor Complexes, Federal State Budgetary Educational Establishment of Higher Education "Bashkir State Agrarian University", Ufa, Russia

*E-mail of corresponding author: gabitovilda@rambler.ru, bgau@ufanet.ru

\section{Resume}

The purpose of this study was to improve the diagnostics efficiency of modern diesel engine injectors with electronic controls. Experimental studies, performed using certified specialized equipment of injectors' manufacturers and standard software packages for data analysis, made it possible to prove adequacy of theoretical research and get results that are more accurate. Those results contribute to development of a software product that allows identifying a particular faulty element during the defective injector's operation by using mathematical processing of the diagnostic data obtained when testing the injector. Thus, the time spent to repair the fuel injection system reduces. The developed software product also helps to predict the remaining injector's operational life and prevent possible technical failures during operation.

\section{Article info}

Received 6 April 2020

Accepted 20 July 2020

Online 19 November 2020

\section{Keywords:}

acceptable values, diagnostic table, injector, nozzle parameters, test mode

\section{Introduction}

Common Rail fuel injection system is widely used in modern automotive and agricultural machinery. In engines with this system, the fuel pressure creation and fuel distribution inside the cylinder occur over time. Since this system is relatively new, manufacturers do not disclose diagnostic technologies. They can give such information only to certified specialized maintenance representatives. Thus, there is a need to develop ways for detecting the elements' working capacity, especially when speaking about the injector, which is the main executive element [1-4].

Various diagnostic methods are used to assess the technical conditions of the fuel supply system (Table 1). These methods are applied in accordance with the diagnostics tasks.

Different diagnostic methods, identifying certain failures and damages (e.g. reduced injection pressure, instability of fuel supply parameters, etc.), are used when checking the working capacity of fuel injection system elements without specifying the location and cause of the failure.

When checking the correct functioning, diagnostics is aimed at determining all the defects in technological adjustments and settings that cause an unacceptable decrease in technical, economic and environmental indicators [5-7].
When searching for defects, diagnostic methods allow identifying the location, type and cause of the defect (wear of plunger elements, fuel delivery and consumption, etc.).

According to the degree of disassembly of an object, there are disassembly and unassembled diagnostic methods.

Disassembly diagnostics is used to assess the mobility of the plunger elements, the spray needle and to measure the wear of various parts of the fuel-delivery systems.

Unassembled diagnostics is usually based on indirect measurements of structural parameters, when installing sensors or diagnostic devices outside the object being diagnosed, without removing it from the diesel engine or on a test stand for fuel-delivery systems [8-11].

Depending on the diagnostic parameters, all the methods are divided into three groups. Thus, some methods are based on measurement parameters, which characterize operation of the entire fuel-delivery system and its component parts, or the co-process. Other methods are based on a direct structural parameter of a part or parts mating.

Diagnostic methods based on work process parameters allow checking the fuel-delivery system output parameters (fuel pressure in the high-pressure line, the stroke of the spray nozzle needle, etc.) and numerous technical characteristics of this system's components (phase parameters of fuel supply and pressure, needle movement speed, flow rate, etc.). Usually, the measurement accuracy of these parameters 
Table 1 Classification of methods for diagnosing the battery fuel-delivery systems

\begin{tabular}{|c|c|}
\hline classification parameters & diagnostic methods \\
\hline diagnosing tasks & $\begin{array}{l}\text { functionality test } \\
\text { tests for proper operation } \\
\text { search for defects }\end{array}$ \\
\hline character of parameter measurement & $\begin{array}{l}\text { direct } \\
\text { indirect }\end{array}$ \\
\hline diagnostics conditions & $\begin{array}{l}\text { field } \\
\text { service station } \\
\text { motorless }\end{array}$ \\
\hline use of diagnostic facilities & $\begin{array}{l}\text { organoleptic } \\
\text { instrumental }\end{array}$ \\
\hline the mode of operation of the object & $\begin{array}{l}\text { in steady state } \\
\text { on non-steady state } \\
\text { in static-dynamic mode }\end{array}$ \\
\hline diagnostic parameters & $\begin{array}{l}\text { work process-related parameters } \\
\text { parameters of related processes } \\
\text { structural parameters }\end{array}$ \\
\hline the frequency of diagnosing & $\begin{array}{l}\text { routine } \\
\text { required } \\
\text { continuous }\end{array}$ \\
\hline by the degree of disassembly of the device under test & $\begin{array}{l}\text { disassembly diagnostics } \\
\text { unassembled }\end{array}$ \\
\hline the physical process being used & $\begin{array}{l}\text { vibro-acoustic } \\
\text { magneto electric } \\
\text { spectrographic; } \\
\text { thermal } \\
\text { hydraulic } \\
\text { gas analytical } \\
\text { kinematic; } \\
\text { other }\end{array}$ \\
\hline
\end{tabular}

is quite high, since in most cases a direct measurement of the controlled physical quantity is performed.

Diagnostic methods based on parameters of related processes make it possible to determine indirectly the same parameters of the work processes, as well as structural parameters of parts and interfaces, if they cannot be directly measured or if their measurement is useless. In this case, the processes' indicators generated by the work processes, are measured. Among these processes are vibration and noise, heating or cooling. This also includes the diagnostic methods for analyzing the fuel contamination by wear products and gas analysis. The accuracy of this measurement of the state parameters is lower than when diagnosing with use of the work process parameters [12-13].

Diagnostic methods, based on the structural parameters, allow determining the wear of parts and gaps in their interfaces and values of the adjustment parameters, by means of direct measurements. Among the parts subject to wear can be precision parts, regulator parts, the housing of the high-pressure fuel pump, camshaft, injection timing coupling, etc. These methods are based on measurement of parts relative motion or geometric dimensions of a part.

According to the physical process used, diagnostic methods are divided into vibro-acoustic, spectrographic, magneto-electric, thermal, hydraulic, gas-analytical and kinematic and some others.
Each method is designed to control a specific physical process and is based on application of a specific physical phenomenon. Classification by the physical process used allows the most complete identification of capabilities and technical characteristics of the corresponding diagnostic method.

A physical process is characterized by a change in physical quantity over time. Hydraulic process is based on pressure; thermal - on temperature; vibro-acoustic-on the amplitude of vibrations at certain frequencies, etc. [14-15].

Currently, many tools for diagnosing injectors have been developed, but they only measure the cycle injection and control flow. If the injector does not meet the requirements, it must be replaced or repaired. The diagnostic methods do not specify procedures for identifying a specific injector fault and the tools used in this case are not designed for its elementby-element study and forecasting the residual life of their operation [16-19].

Quality of the diesel engine operation depends directly on quality of the fuel supply system and each of its elements. Quality of those elements is determined by a set of technical parameters that depend on a number of factors: climate conditions, the adopted system of maintenance and repair, the volume and nature of the work performed, quality of implementation of the rules of operation and maintenance of machines, quality and availability of technical means of 


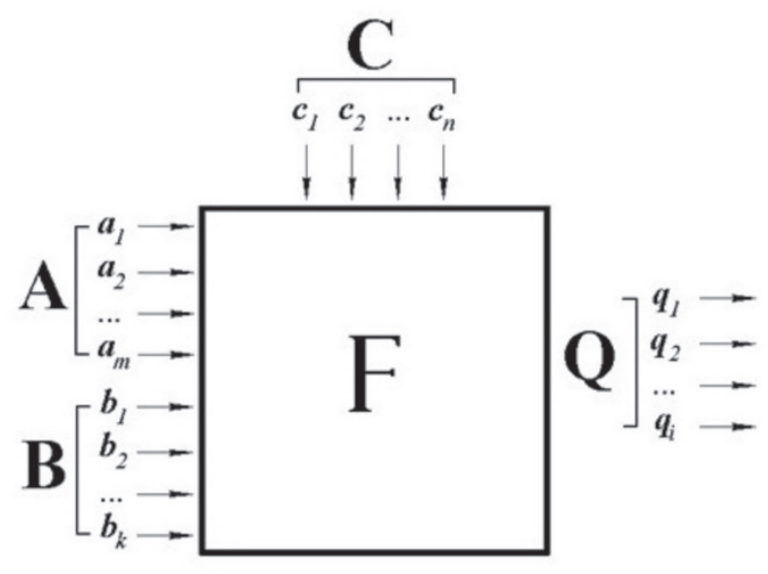

Figure 1 Information model of injector operation

service and technical documentation, etc. Because of this, the control over the technical parameters conditions can be considered as a way and method of influencing these indicators of the work quality and reliability of the node during its service life.

By the control over the technical conditions of the fuel equipment elements, as well as injectors, warning failures, manipulations aimed at restoring nominal values and maintaining all the parameters within the tolerance of the operational state should be meant. Thus, a diesel injector can be considered as an object that is affected by various operational factors and has certain patterns of changes in technical conditions.

Effective methods implemented in various automated installations, diagnostic devices and testers cannot be applied in practice without preliminary measures to improve suitability of both diagnostic tools and diesel engine and its fuel-delivery systems. Improving the suitability of fueldelivery systems to basic diagnostic tools allows reducing the number of adapter units, to make sensors installation on the object easier and to increase efficiency of diagnostics [20-22].

In general, it should be noted that these devices and diagnostic tools make it possible to evaluate only one delivery line for one inspection cycle. They neither provide specific data on the resource and the probable defect, nor indicate a specific defect. They do not provide a full picture of many diagnostic parameters. As a result, it is difficult to analyze the information received when diagnosing an element of the fuel-delivery systems. Thus, it is necessary to develop modern diagnostic tools and their software, i.e. electronic automated systems.

Electronic automated systems create conditions that allow solving problems of diagnostics on a fundamentally new industrial basis. It means that nearly all the operations of technical diagnostics will be performed by electronic installation blocks. The end result on the composition of the object will inform of the object quality class by means of such words as "fit" "unfit", "normal", "less than normal", "more than normal" etc. At the same time, the diagnostics process can be carried out continuously according to a preset optimal program in a particular logical sequence [4, 23-24].
A brief review and analysis of the problem showed that a certain scientific and technical basis has been created for ensuring reliability and evaluating the quality of fuel equipment while in operation. At the same time, existing technologies and methods for diagnosing, monitoring and evaluating the technical condition of electrically-controlled elements of modern fuel-delivery systems do not take due account of their performance features.

Improving the reliability and reducing the complexity of diagnostic work can be achieved by developing automated tools capable to digitize data obtained by direct determination. The data are then processed using a mathematical apparatus ensuring diagnosis that is more accurate by increasing the number of compared parameters while the number of sensors is constant.

The study aims at analyzing the injector work process to define the influence of its various design parameters on performance, conducting theoretical and experimental studies of an effect of the injector structural parameters on diagnostic parameters, developing an effective way of injector diagnosing to estimate the injector working parameters and predict its residual resource based on scientific research.

\section{Material and Methods}

\subsection{Mathematical model}

The information model of the diesel injector operation should be presented in the form of a multi-parameter system (Figure 1).

To analyze the injector operation, A, B, C correction factors are considered. They are determined by structural and diagnostic parameters. In this case, in the system under consideration, input $\mathrm{A}\left(\mathrm{a}_{1}, \mathrm{a}_{2}, \ldots, \mathrm{a}_{\mathrm{n}}\right)$ is unmanaged. Components of vector A should include: natural and climatic conditions, air humidity, environmental temperature fluctuations, fuel quality, etc. Components of the input B vector $\left(b_{1}, b_{2}, \ldots, b_{m}\right)$ are corrective and change during operation. They are the spring force, the value of moving elements displacement, the hydraulic density of precision 


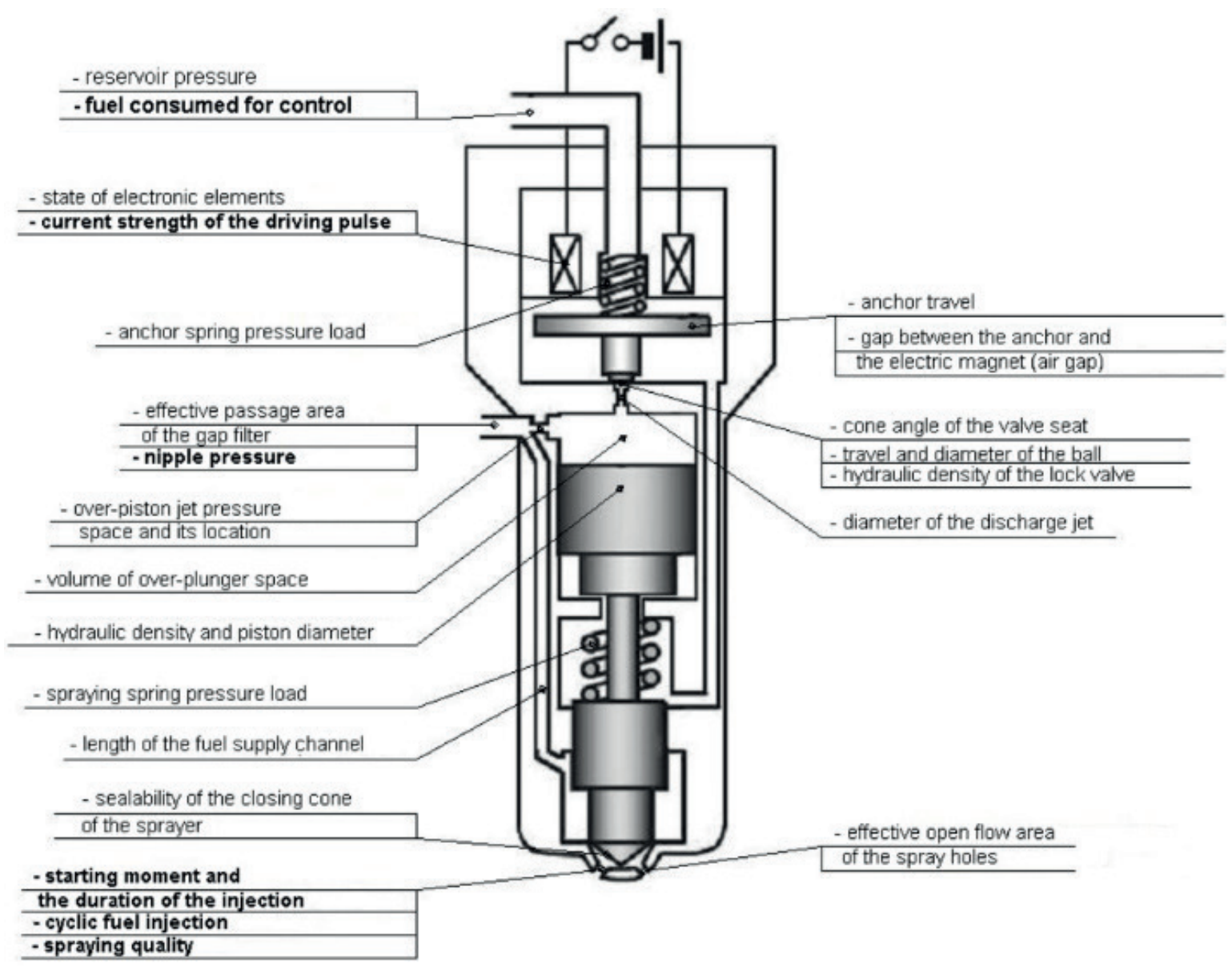

Figure 2 Structural and diagnostic (bold type) parameters of the diesel engine injector

parts, etc. Among control factors of the model are such components of the $\mathrm{C}$ vector $\left(\mathrm{b}_{1}, \mathrm{~b}_{2}, \ldots, \mathrm{b}_{\mathrm{k}}\right)$ as pulse frequency and duration, ramp fuel pressure, etc. [1, 4, 14].

The value of the output $Q$ vector depends on the state of the input parameters according to a certain pattern:

$\mathrm{Q}=\mathrm{F}\{\mathrm{A}, \mathrm{B}, \mathrm{C}\}$,

where $\mathrm{F}$ is a conversion operator for the three vector arguments that defines the system's optimization criterion.

If the actual generalized estimator of the injector state quality $\mathrm{Q}_{\mathrm{f}}$ and the set of its estimators $\mathrm{q}_{\mathrm{fi}}$ are less than or equal to its tolerance values ${ }_{\mathrm{Qtol}}$ and $\mathrm{q}_{\mathrm{i} \text { tol }}$, respectively, then it can be considered that the injector functions in accordance with the established requirements and is in good technical condition.

Criteria for the normal functioning of the system can be defined as follows:

$\mathrm{q}_{\mathrm{fi}} \leq\left[\mathrm{q}_{\mathrm{itol}}\right] ; \mathrm{Q}_{\mathrm{f}} \leq\left[\mathrm{Q}_{\mathrm{tol}}\right]$

To improve the quality of diagnostics, injector operation parameters, determined by diagnostics, must contain quantitative characteristics that can be evaluated within the tolerance values. Any deviation of the system parameters from the acceptable values that occurs during operation is compensated by the influence of $\mathrm{C}$ control factors. If this is not sufficient, the system can return to normal operation both by changing $\mathrm{B}$ corrective factors and by performing repair or adjustment actions.

\subsection{Operation analysis}

The tolerance values of the structural and diagnostic injector parameters were accepted as the operation estimators of the system under consideration.

In this paper, the object of research is a $\mathrm{BOSCH}$ injector of the battery fuel-delivery system. This injector was completely demounted in order to analyze its working surfaces, the principle of its operation and the purpose of its each part. For example, a ball lock valve controls the pilot piston movement. When the lock valve is closed, the fuel pressure in the over-plunger cavity affects the upper surface of the pilot piston, which makes it move towards the closed atomizer. When the valve opens, the pressure in the over-plunger cavity drops and the fuel is dumped. When the fuel pressure in the cavity under the needle increases, the spray needle and the pilot piston are lifted. The working surface of the lock ball valve is the "cone seat - ball" coupling surface, which is determined by the state of the seat and ensures that high pressure is maintained 


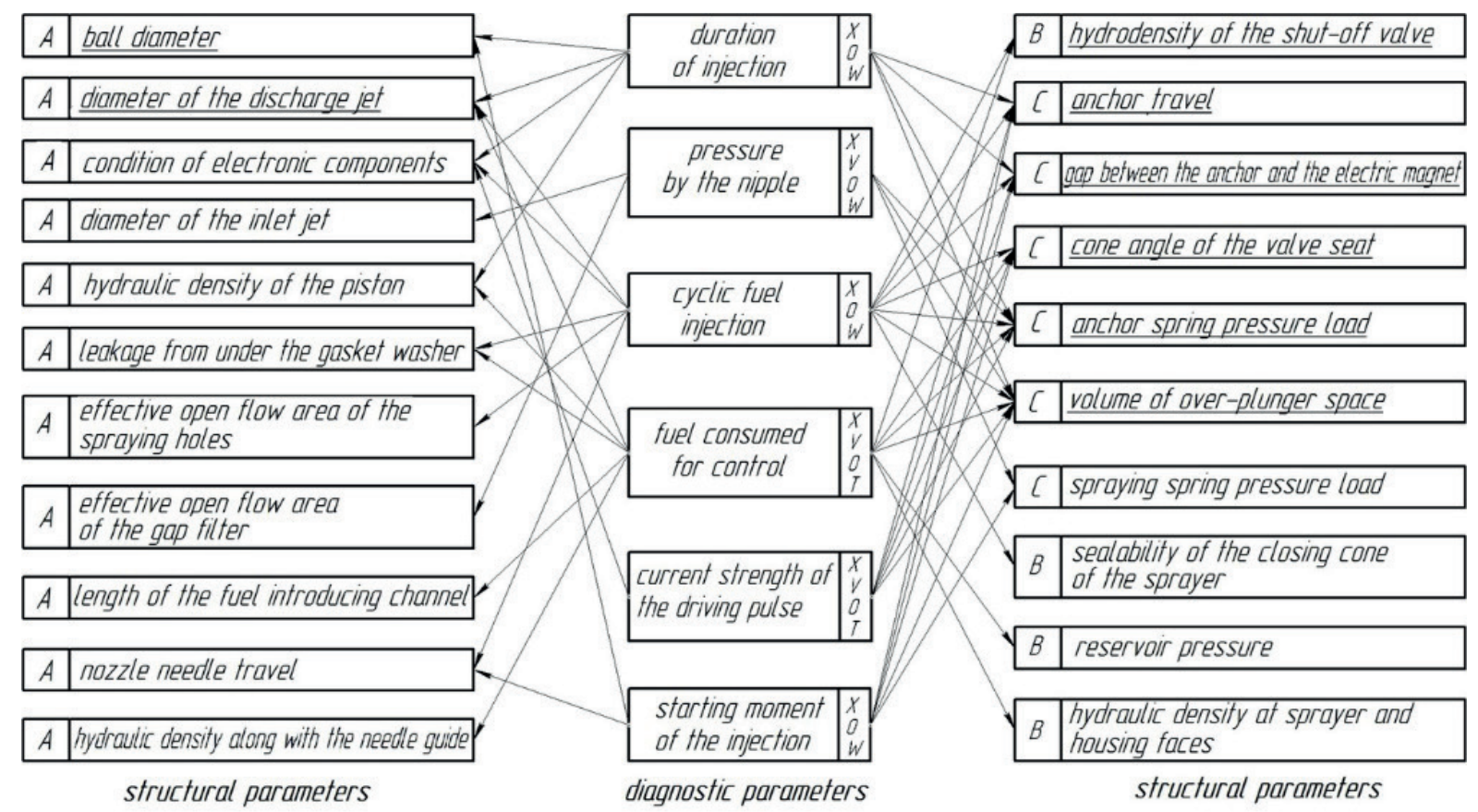

Figure 3 Mutual effects of diagnostic and structural parameters
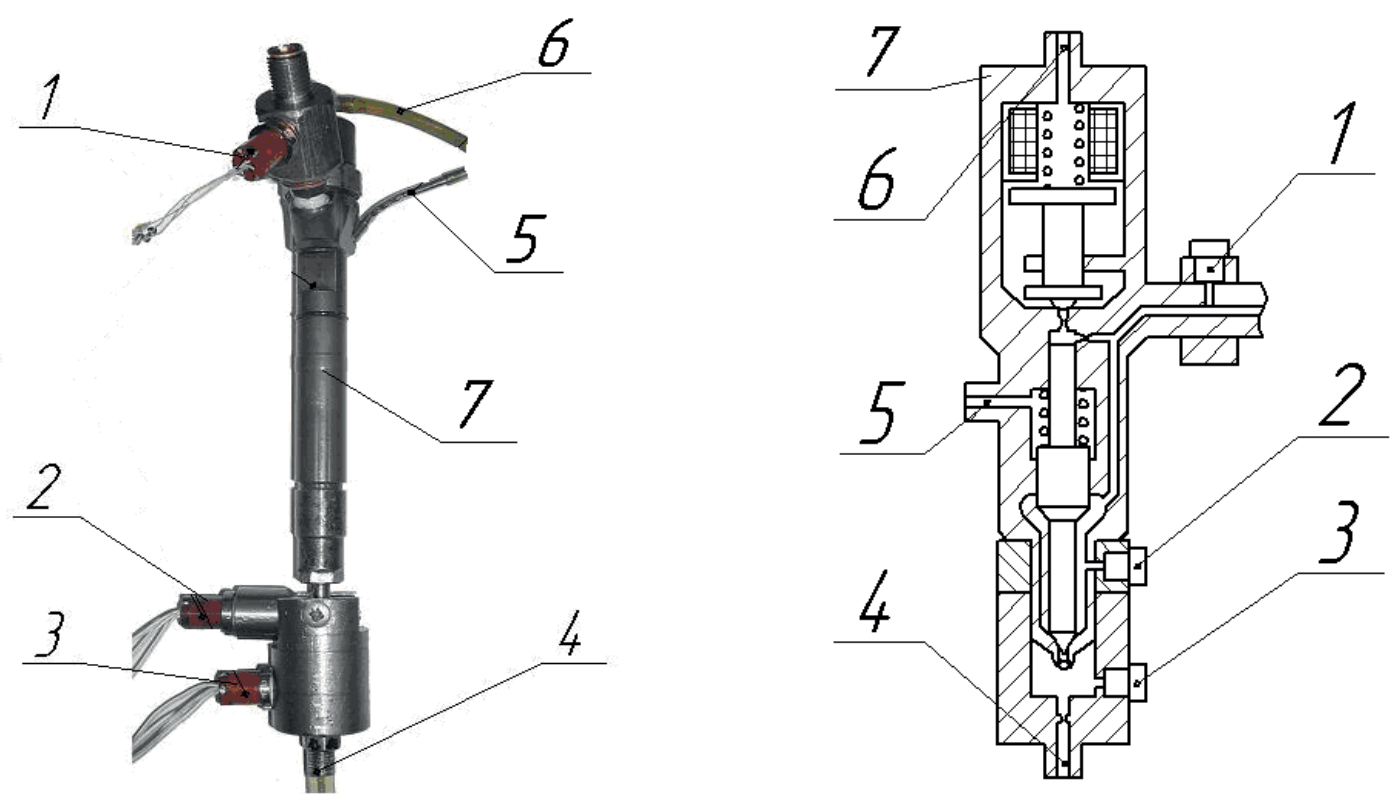

Figure 4 General view of the experimental injector (a) and sensors location on the nozzle (b): 1, 2, 3- pressure sensors at the inlet, under the needle sensors and the beginning of injection sensors, respectively; 4, 5, 6 - measurement of the cyclic supply, leaks on the sealing washers, the fuel consumption for control; 7 - the injector

in the over-plunger cavity. The amount of fuel needed for control is also determined by the lock valve range, which is adjusted by changing the thickness of the washers installed between the valve-stem guide housings and the tapered seat. Other parts were reviewed in a similar way. A detailed analysis of a BOSCH injector design allowed describing 21 structural and 6 diagnostic parameters (Figure 2).

Parameters that change spontaneously during the operation, or are corrected using adjustments during the maintenance, were taken as structural parameters. For example, the spray needle hydro-density is reduced due to wear, or the gap between the anchor and the electromagnet, which is adjusted using washers. Diagnostic parameters are those that can be measured without disassembling the injector. For example, injection rate can be determined using a stand flow meter. A clamp meter is used to measure the current strength of the driving pulse [13, 25-26].

To improve efficiency of the repair work, methods for assessing the state of each structural parameter were determined. For example, they can be determined directly on the engine $(\mathrm{V})$, on stands (X) or by disassembling $(\mathrm{O})$, respectively. At the same time the need to dismantle and install the injector (W), as well as the possibility of abandoning these operations were considered (T). Each of 

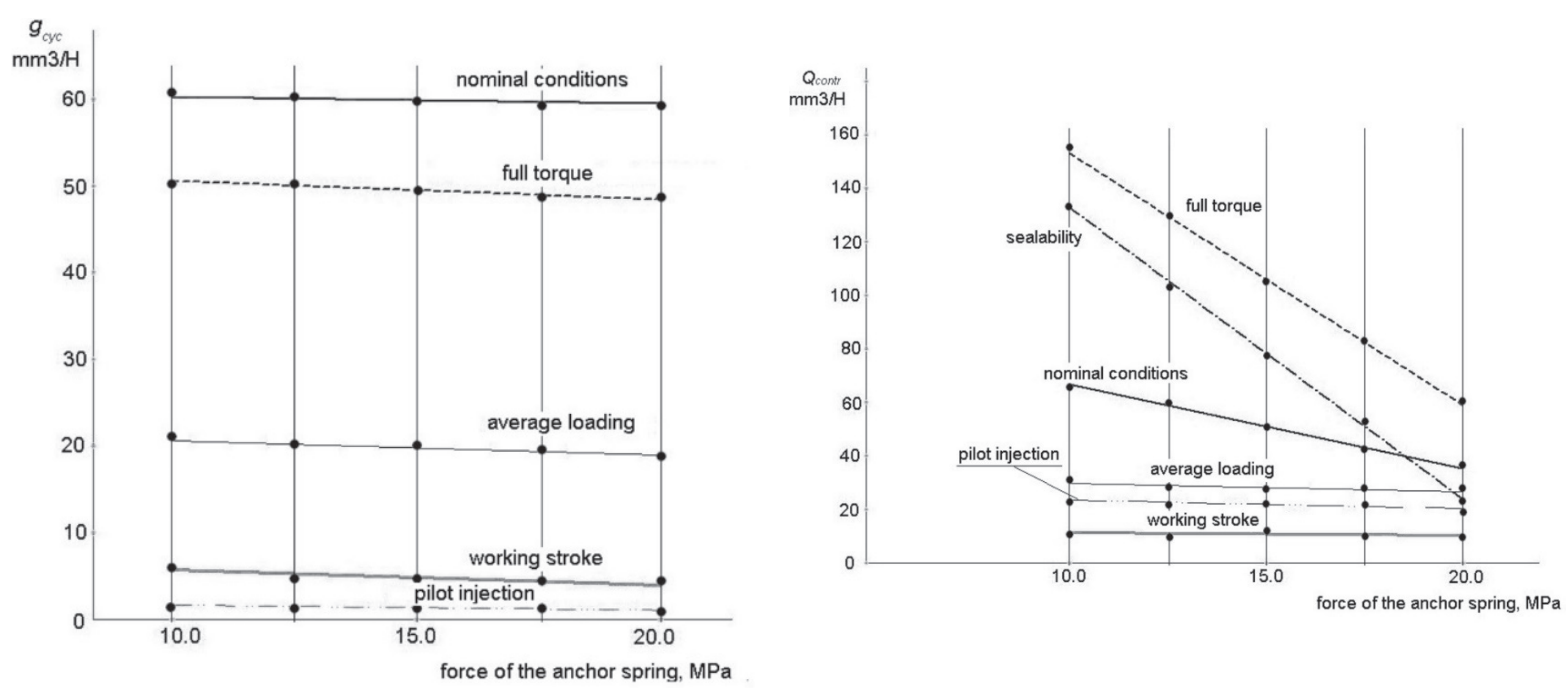

Figure 5 Dependence of the cyclic fuel injection $g_{c}$ in $\mathrm{mm}^{3} /$ cycle (a) and fuel consumption for control $Q_{\text {contr }}$ in $\mathrm{mm}^{3} / \mathrm{cycle}$ (b) on the anchor spring force in different modes

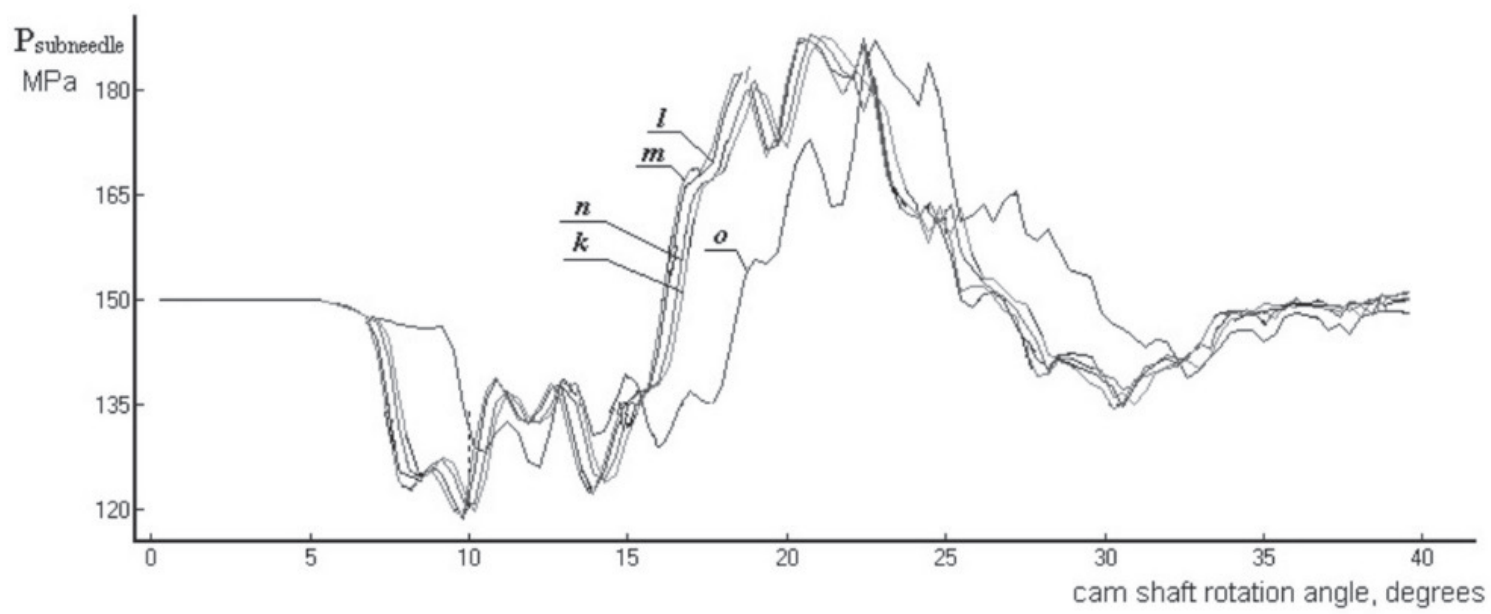

Figure 6 Change of pressure in the sub needle space in one cycle depending on the half angle of the cone $\alpha$ : $k-\alpha=30^{\circ} ; l-\alpha=40^{\circ} ; m-\alpha=55^{\circ} ; n-\alpha=60^{\circ} ; o-\alpha=70^{\circ}$

the structural parameters can be changed by replacing (A), restoring (B), or adjusting parts (C).

In order to determine the effect of changes in each structural parameter on changes in diagnostic parameters, an additional analysis was performed. During this analysis, the processes occurring inside the injector was studied. The analysis showed that the parameters have mutual influence according to diagram in Figure 3.

\subsection{Experimental studies}

The next stage of scientific work consisted of experimental studies of changes in all the diagnostic parameters under the influence of one of the structural parameters. Non-motor tests were carried out in accordance with ISO 9002 test plans using a specialized EPS 815 dieselfuel equipment stand, used for adjusting and testing and a Bosch KMA 802 electronic measuring system with a CRI retrofit kit used for the Common Rail injectors testing. For experimental studies, some changes were made to design of the injector (Figure 4). A distinctive feature of this injector is its ability to determine the moment of injection start, measure the pressure under the injector needle and leaks on the sealing washers of the nozzle body, regardless of the fuel consumption for control.

As an example, some of the numerous dependencies obtained are shown.

Dependence of the value of cyclic injection and fuel consumed for control on the force of the anchor spring is shown in Figure 5. Analyzing the graph of dependence of the GC fuel cyclic injection and the fuel consumption, for the Qcontr control from the spray spring force, one can say that when the starting torque of the injector nozzle needle increases, the cyclic injection decreases and in some modes, there is a complete stop of the GC fuel supply. This is due to an increase in the load acting on the spray needle, which in some modes exceeds the force from the pressure in the fuel system. Thus, the spray needle does not open the spray holes. The most informative modes for this structural parameter are the cyclic injection at medium loads and the fuel consumption for control at maximum 


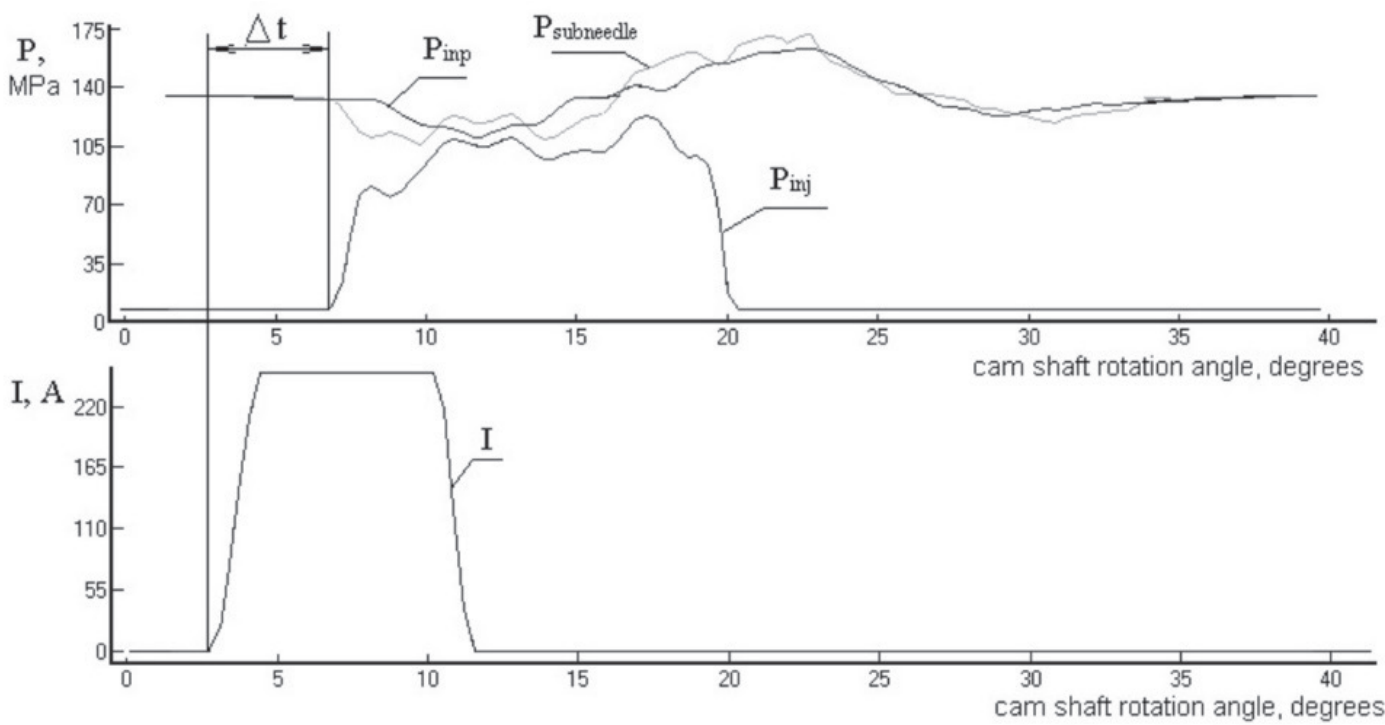

Figure 7 Determining the injection delay parameter from the moment the control pulse is applied: $I$ - current strength; $p_{\text {overpl }}$ - pressure in the over-plunger cavity; $p_{i n p}$ - pressure at the nipple; $p_{\text {inj }}$ - fuel injection pressure; $p_{\text {subneedle }}$ - pressure in the sprayer

Table 2 Changes in the EGF diagnostic parameters when the structural parameters in the nominal mode are changed

\begin{tabular}{|c|c|c|c|c|c|c|}
\hline \multirow{2}{*}{ structural parameter } & \multicolumn{6}{|c|}{ diagnostic parameter } \\
\hline & $Q_{\text {contr }}$ & $\mathrm{I}_{\mathrm{em}}$ & $\Delta \mathrm{t}$ & $\mathrm{g}_{\mathrm{c}}$ & $t_{\text {inj }}$ & $\mathrm{P}_{\text {inp }}$ \\
\hline the force of the sprayer spring & $\uparrow$ & - & $\uparrow$ & $\downarrow$ & $\downarrow$ & $\uparrow$ \\
\hline hydraulic density of the sprayer & $\uparrow$ & $\uparrow$ & - & - & $\uparrow$ & - \\
\hline effective passage area of the sprayer & $\downarrow$ & - & $\downarrow$ & $\uparrow$ & $\uparrow$ & $\downarrow$ \\
\hline sealability of the closing cone of the sprayer & $\uparrow$ & - & $\uparrow$ & $\downarrow$ & $\uparrow$ & $\uparrow$ \\
\hline anchor travel & $\uparrow$ & - & $\downarrow$ & $\uparrow$ & $\uparrow$ & - \\
\hline air gap & $\uparrow$ & $\uparrow$ & $\uparrow$ & $\uparrow$ & - & - \\
\hline effective passage area of the gap filter & $\uparrow$ & - & $\uparrow$ & $\uparrow$ & $\uparrow$ & $\downarrow$ \\
\hline angle of the valve seat cone & $\uparrow$ & $\downarrow$ & $\uparrow$ & $\downarrow$ & - & $\uparrow$ \\
\hline ball diameter & $\downarrow$ & $\downarrow$ & $\uparrow$ & $\downarrow$ & - & - \\
\hline length of the fuel introducing channel & - & - & - & - & - & - \\
\hline hydraulic density at the front surface of the sprayer & $\uparrow$ & - & $\downarrow$ & $\downarrow$ & $\downarrow$ & $\downarrow$ \\
\hline nozzle needle travel & $\uparrow$ & - & - & $\uparrow$ & $\uparrow$ & $\downarrow$ \\
\hline drain pressure & $\uparrow$ & - & - & $\downarrow$ & $\downarrow$ & - \\
\hline condition of electronic parts & $\uparrow$ & - & $\uparrow$ & $\downarrow$ & - & - \\
\hline force of the anchor spring & $\downarrow$ & - & $\uparrow$ & $\downarrow$ & $\downarrow$ & $\uparrow$ \\
\hline diameter of the spraying nozzle in the over-piston space & $\uparrow$ & - & $\uparrow$ & $\downarrow$ & $\downarrow$ & - \\
\hline hydraulic density of the piston & $\downarrow$ & - & $\downarrow$ & $\downarrow$ & $\downarrow$ & $\uparrow$ \\
\hline leaks on the sealing washer & $\uparrow$ & - & $\uparrow$ & $\downarrow$ & $\downarrow$ & $\downarrow$ \\
\hline volume of over-plunger space & $\uparrow$ & - & $\uparrow$ & $\uparrow$ & - & $\uparrow$ \\
\hline
\end{tabular}

torque. Graphs show that the force of the anchor spring has a pronounced effect on the fuel consumption for control. This is influenced by an increase in the force on the ball valve bases and consequently on the reaction to the fuel pressure in the over-plunger cavity.

To clarify the scientific research, measurements of the pressure values in the injector cavities, at different operating modes of fuel supply systems, were made. The graph shows one of the many graphs obtained when changing the structural parameters of the injectors (Figure 6).

Analysis of the average injection characteristics for different values of the half-angle of the valve seat cone showed that when the angle of the valve seat of the cone increases, the characteristic first improves, but after 
Table 3 Influence of the injector structural parameters exceeding the limits on the injector diagnostic parameters (idle mode)

\begin{tabular}{|c|c|c|c|c|c|c|}
\hline \multirow{2}{*}{ structural parameter } & \multicolumn{6}{|c|}{ diagnostic parameter } \\
\hline & $Q_{\text {contr }}$ & $\mathrm{I}_{\mathrm{em}}$ & $\Delta \mathrm{t}$ & $\mathrm{g}_{\mathrm{c}}$ & $t_{\text {inj }}$ & $\mathrm{P}_{\text {inp }}$ \\
\hline the force of the sprayer spring & $\uparrow$ & - & $\uparrow$ & $\downarrow$ & $\downarrow$ & $\uparrow$ \\
\hline hydraulic density of the sprayer & $\uparrow$ & - & $\downarrow$ & $\downarrow$ & $\uparrow$ & $\downarrow$ \\
\hline effective passage area of the sprayer & $\downarrow$ & - & $\downarrow$ & $\uparrow$ & $\uparrow$ & - \\
\hline sealability of the closing cone of the sprayer & $\uparrow$ & - & - & $\downarrow$ & $\uparrow$ & - \\
\hline anchor travel & $\uparrow$ & - & - & $\uparrow$ & $\uparrow$ & - \\
\hline air gap & $\uparrow$ & $\uparrow$ & $\uparrow$ & $\uparrow$ & - & - \\
\hline effective passage area of the gap filter & $\uparrow$ & - & - & $\uparrow$ & $\uparrow$ & - \\
\hline angle of the valve seat cone & $\uparrow$ & $\downarrow$ & - & $\downarrow$ & - & - \\
\hline ball diameter & $\downarrow$ & $\downarrow$ & $\uparrow$ & $\downarrow$ & - & - \\
\hline length of the fuel introducing channel & - & - & - & - & - & - \\
\hline hydraulic density at the front surface of the sprayer & $\uparrow$ & - & $\downarrow$ & $\downarrow$ & $\downarrow$ & $\downarrow$ \\
\hline nozzle needle travel & $\uparrow$ & - & - & $\uparrow$ & & - \\
\hline drain pressure & $\uparrow$ & - & - & $\downarrow$ & $\downarrow$ & - \\
\hline condition of electronic parts & $\uparrow$ & - & - & $\downarrow$ & - & - \\
\hline force of the anchor spring & $\downarrow$ & - & $\uparrow$ & $\downarrow$ & $\downarrow$ & $\downarrow$ \\
\hline diameter of the spraying nozzle in the over-piston space & $\uparrow$ & - & - & $\downarrow$ & $\downarrow$ & - \\
\hline hydraulic density of the piston & $\downarrow$ & - & - & $\downarrow$ & $\downarrow$ & - \\
\hline leaks on the sealing washer & $\uparrow$ & - & $\uparrow$ & $\downarrow$ & $\downarrow$ & $\downarrow$ \\
\hline volume of over-plunger space & $\uparrow$ & - & - & $\uparrow$ & $\downarrow$ & - \\
\hline
\end{tabular}

$\alpha=55^{\circ}$ it decreases again. The critical value for this structural parameter is $\alpha>65^{\circ}$, since it is at this value that the fuel supply parameter leaves the tolerance zone. This is due to a decrease in fuel consumption through the shut-off valve, since its effective flow section reduces together with the flow capacity of the valve, which leads to a delay in lifting the control plunger and, accordingly, a delay in the start of fuel injection.

When performing experiments and processing results, a new diagnostic parameter "injection delay $\Delta \mathrm{t}$ " was introduced that characterizes the period from the start of the pulse to the start of injection. This period depends on the speed of the processes in the injector and directly characterizes the state of some of its elements. The retardation value depends mainly on the mobility of the elements (hanging, jamming) and the channels and valve transport capacity (Figure 7). A new concept of injection delay is introduced to obtain the updated data for diagnosing injectors. It depends on the speed of the injector elements. This diagnostic parameter shows the condition of the holes and the mobility of the elements.

\section{Results and discussion}

The data obtained made it possible to conduct a complete analysis of influence of each diagnostic parameter on the structural change in different operating modes of the diesel engine (nominal, start-up, maximum torque and idling). If value of the diagnostic parameter does not exceed the allowed deviations, then a particular diagnostic parameter in this mode is not informative in relation to a particular structural parameter, then the "- " sign is written. If the value is higher than the allowed value and this is due to an increase in the structural parameter, then the sign " $\uparrow$ " is written in the Table 2 (direct dependence), if it is lower than the allowed value, then the sign " $\downarrow$ " is used (inverse dependence). If the value exceeds the limit, which is caused by an increase in the structural parameter then the sign is written in the Table 3 . If the dependence is reversed, then the $\downarrow$ sign is used [4, 12-13, 25].

As a result, for the first time, fault Tables 2-3 with corrected structural parameters in the course of experimental studies were obtained. Table 4 allows analyzing the state of the injector for different operating modes.

The full cycle of diagnostics is performed by determining diagnostic indicators for the three main modes of injector operation, which can be completed on the engine and on specialized stands. Experimental studies have shown that use of the full volume injector tests for diagnosis of certain defects may be excessive. During the data processing from initial tests, after obtaining a guaranteed conclusion about the state of the diesel injector, the diagnosis process may be completed ahead of time. 
Table 4 Influence of the injector structural parameters exceeding the limits on the injector diagnostic parameters (start mode)

\begin{tabular}{|c|c|c|c|c|c|c|}
\hline \multirow{2}{*}{ structural parameter } & \multicolumn{6}{|c|}{ diagnostic parameter } \\
\hline & $\mathrm{Q}_{\text {contr }}$ & $\mathrm{I}_{\mathrm{em}}$ & $\Delta \mathrm{t}$ & $\mathrm{g}_{\mathrm{c}}$ & $t_{\text {inj }}$ & $\mathrm{P}_{\text {inp }}$ \\
\hline the force of the sprayer spring & $\uparrow$ & - & $\uparrow$ & $\downarrow$ & $\downarrow$ & $\uparrow$ \\
\hline hydraulic density of the sprayer & $\uparrow$ & - & $\downarrow$ & $\downarrow$ & $\uparrow$ & $\uparrow$ \\
\hline effective passage area of the sprayer & $\downarrow$ & - & $\downarrow$ & $\uparrow$ & $\uparrow$ & - \\
\hline sealability of the closing cone of the sprayer & $\uparrow$ & - & - & $\downarrow$ & $\uparrow$ & - \\
\hline anchor travel & $\uparrow$ & - & $\downarrow$ & $\uparrow$ & $\uparrow$ & - \\
\hline air gap & $\uparrow$ & $\uparrow$ & $\uparrow$ & $\uparrow$ & - & - \\
\hline effective passage area of the gap filter & $\uparrow$ & - & - & $\uparrow$ & $\uparrow$ & - \\
\hline angle of the valve seat cone & $\uparrow$ & $\downarrow$ & $\uparrow$ & $\downarrow$ & - & $\uparrow$ \\
\hline ball diameter & $\downarrow$ & $\downarrow$ & $\uparrow$ & $\downarrow$ & - & - \\
\hline length of the fuel introducing channel & - & - & - & - & - & - \\
\hline hydraulic density at the front surface of the sprayer & $\uparrow$ & - & $\downarrow$ & $\downarrow$ & $\downarrow$ & $\downarrow$ \\
\hline nozzle needle travel & $\uparrow$ & - & - & $\uparrow$ & $\uparrow$ & - \\
\hline drain pressure & $\uparrow$ & - & - & $\downarrow$ & $\downarrow$ & $\downarrow$ \\
\hline condition of electronic parts & $\uparrow$ & - & - & $\downarrow$ & - & - \\
\hline force of the anchor spring & $\downarrow$ & - & $\uparrow$ & $\downarrow$ & $\downarrow$ & - \\
\hline diameter of the spraying nozzle in the over-piston space & $\uparrow$ & - & $\downarrow$ & $\downarrow$ & $\downarrow$ & $\downarrow$ \\
\hline hydraulic density of the piston & $\downarrow$ & - & $\downarrow$ & $\downarrow$ & $\downarrow$ & $\downarrow$ \\
\hline leaks on the sealing washer & $\uparrow$ & - & $\uparrow$ & $\downarrow$ & $\downarrow$ & $\downarrow$ \\
\hline volume of over-plunger space & $\uparrow$ & - & - & $\uparrow$ & $\downarrow$ & - \\
\hline
\end{tabular}

Based on results of Tables 2-4, a specific injector fault can be pointed out. In other words, when the diagnostic parameter exceeds the limit in one direction or another, a structural parameter that has gone out of the permissible deviation limit from the set value and requires adjustment or replacement can be identified. For example, an increase in fuel consumption for control may be caused by wear on the seat of the ball valve or by a decrease in the anchor spring force.

In this study, a well-known method for diagnosing elements of diesel fuel equipment was applied. This method is used by manufacturers for their products and it represents a common hydrodynamic calculation of fuel injection systems [25-34]. A distinctive feature of this method compared to traditional methods is addition of a detailed analysis of the closing valve of the injector into theoretical studies. This made it possible to obtain more accurate tolerance values for the structural parameters of the injector, which allowed preserving its performance, as well as the diesel engine working capacity as a whole. Implementation of the obtained data into the standard software of diagnostic stands of fuel equipment will increase efficiency of the injectors diagnostics and will provide a more accurate diagnosis of state of its elements. As mentioned above, this method of research can be applied to other units of the engine and fuel system of various manufacturers.
Currently various stands for testing injectors of the battery fuel injection systems are being developed. These stands assess the quality of their operation using only a few parameters: cyclic injection, fuel consumed for control, sometimes injection quality [1, 5, 8-9, 11, 17, 24, 28]. These technological recommendations are provided by the manufacturers. However, this method of diagnosis only gives two test results - a "working" and a "non-working" injector. This diagnostics is sufficient for employees of specialized services, but it increases the detection of a specific injector fault and working hours for troubleshooting. Reduction in the cost of operations is due to an accurate diagnosis of the injector condition, which in turn reduces the time spent on its repair.

\section{Conclusions}

As a part of the study, the injector's work process was examined and theoretically described, taking account wear of parts during its operation. Based on this, the classical hydrodynamic calculation process of fuel injection was refined. The resulting mathematical model of injector's operation allowed calculating the permitted deviations of specific structural parameters of the injector and determining the test modes in which this effect is most pronounced. Because of a comprehensive analysis of the design and work process of the BOSCH injector, 
20 structural and 6 diagnostic parameters were identified. By studying these parameters, Tables 2-4 of faults for different modes of operation of the diesel engine (nominal, start, idling) were made, which also contains justification of the conditions for ensuring the injector operability by adjusting, restoring or replacing any part.

Experimental studies have corrected and confirmed values of allowed deviations of structural parameters and revealed their relationship with diagnostic parameters. Using the obtained results, made it possible to identify a specific faulty element based on data obtained during the random diagnostics of the injector. Results allow not only to identify a specific faulty element in the case of the bad injector operation, which reduces the complexity of repair of the resistant temperature device, but also to predict the remaining injector life, to prevent possible failures and downtime of equipment during the hard agricultural work.

The resulting method of diagnostics makes it possible to carry out tests for the malfunctions of individual units of the fuel-delivery systems and injectors of other manufacturers such as Denso and Delphi. For the first time, the permitted deviations of structural parameters for the BOSCH injector were obtained. All of the tolerance values of the injector's structural parameters are noticeable, and the test mode in which its influence is most observed is determined for each of them.

\section{References}

[1] ANANIN, A. D., MIKHLIN, V. M., GABITOV, I. I. Diagnostics and maintenance of machines. Textbook. Moscow: Academy, 2015. ISBN 978-5-4468-0769-7.

[2] GABITOV, I. I., INSAFUdDINOV, S. Z., KHARISOV, D. D., SAFIN, F. R., NEGOVORA, A. V., YUNUSBAEV, N. M., AKHMETOV, A. F., FARHUTDINOV, T., SHARAFEEV A. Diagnostics and regulation of fuel equipment of diesels on stands with injection to medium with counter-pressure. Journal of Engineering and Applied Sciences [online]. 2018, 13(S11), p. 8782-8788. ISSN 1816-949X, eISSN 1818-7803. Available from: https://doi.org/10.3923/jeasci.2018.8782.8788

[3] GABITOV, I. I., SAIFUllin, R. N., FARHSHATOV, M. N., NEGOVORA, A. V., MUDARISOV, S. G., KHASANOV, E. R., GALIULLIN, R. R., GABDRAFIKOV, F. Z., YUNUSBAEV, N. M., VALIEV A. R. Hardening of electrohydraulic injectors valve units of diesels at repair. Journal of Engineering and Applied Sciences [online]. 2018, 13(S8), p. 6478-6486. ISSN 1816-949X, eISSN 1818-7803. Available from: https://doi.org/10.3923/jeasci.2018.6478.6486

[4] SKAKOV, M., RAKHADILOV, B., SCHEFFLER, M., BATYRBEKOV, E. Microstructure and tribological properties of electrolytic plasma nitrided high-speed steel. Materials Testing [online]. 2015, 57(4), p. 360-364. ISSN 0025-5300. Available from: https://doi.org/10.3139/120.110709

[5] GRITSUK, I. V., ZENKIN, E. Y., BULGAKOV, N., GOLOVAN, A., KURIC, I., MATEICHYK, V., SAGA, M., VYCHUZHANIN, V., SYMONENKO, R., RABINOVICH, E., PAVLENKO, V., POHORLETSKYI, D. The complex application of monitoring and express diagnosing for searching failures on common rail system units SAE Technical Paper [online], 20182018-011773. ISSN 0148-7191, eISSN 2688-3627. Available from: https://doi.org/10.4271/2018-01-1773

[6] KULMANAKOV, S. P., LEBEDEVAS, S., KULMANAKOV, S. S., LAZAREVA, N., RAPALIS, P. Comparative studies of the biodiesel fuel jet development dynamics in common rail and conventional design fuel systems. Transport [online]. 2019, 34(1), p. 67-74. ISSN 1648-4142, eISSN 1648-3480. Available from: https://doi.org/10.3846/transport.2019.7223

[7] MALASTOVSKII, N. S., BARChENKO, F. B., GREKHOV, L. V., KUlESHOV, A. S., DENISOV, A. A., STARKOV, E. E. Formation of requirements for high-speed diesel injection characteristics in order to reduce toxicity. Engineering Journal: Science and Innovation [online]. 2017, 3(63), p. 1-19. ISSN 2308-6033. Available from: https://doi.org/10.18698/2308-6033-2017-3-1594

[8] POGUlYAEV, Y. D., BAITIMEROV, R. M., ROZHDESTVENSKII, Y. V. Detailed dynamic modeling of common rail piezo injector. Procedia Engineering. [online]. 2015, 129, p. 93-98. ISSN 1877-7058. Available from: https://doi.org/10.1016/j. proeng.2015.12.014

[9] MAIORANA, G., SEBASTIANO, G. R., UGAGLIA, C. Common rail system for passenger car / Die common-rail-motoren von Fiat (in German). MTZ-Motortechnische Zeitschrift [online]. 1998, 59(9), p. 582-588. ISSN 0024-8525. Available from: https://doi.org/10.1007/BF03251382

[10] WU, D. W., SUN, B. G., XU D. Deformation of nozzle, needle, and control plunger of solenoid fuel injector under high injection pressure. Proceedings of the Institution of Mechanical Engineers, Part D: Journal of Automobile Engineering [online]. 2019, 233(7), p. 1767-1782. ISSN 0954-4070, eISSN 2041-2991. Available from: https://doi.org/10.1177\%2F0954407018786354

[11] HOFFMANN, K.-H., HUMMEL, K., MADERSTEIN, T. The common rail injection system - a new chapter in diesel injection technology / Das Common-Rail-Einspritzsystem -ein neues Kapitel der Dieseleinspritz-Technik (in German). MTZ: Motortechnische Zeitschrift. 1997, 10(58), p. 572-582. ISSN 0024-8525.

[12] MALASTOWSKI, N. S., BARCHENKO, F. B., GREKHOV, L. V., KULESHOV, A. S. Shaping of injection rate for reducing emission level of high-speed engine. International Journal of Applied Engineering Research. 2016, 11(23), p. 11189-11198. ISSN 0973-4562. 
[13] MARCOV, V., GLADYSHEV, S., DEVIANIN, S. Injector tip design improvement of the diesel injectors. SAE Technical Paper [online], 2011, 2011-01-1397. ISSN 0148-7191, eISSN 2688-3627. Available from: https://doi.org/10.4271/2011-011397

[14] NIGMATUlLIN, S. F., KOSTAREV, K. V., KARACHURIN, B. S. Studies on the effect of the process fluid temperature on the cycle flow of an electrohydrocontrolled nozzle. Bulletin of Bashkir State Agrarian University. 2015, 3(35), p. 69-71.

[15] WIARTALLA, A., RUHKAMP, L., KOERFER, T., TOMAZIC, D., TATUR, M., KOEHLER, E. Future emission demands for ship and locomotive engines-challenges, concepts and synergies from HD-applications. In: 26th CIMAC World Congress on Combustion Engine: proceedings. 2010. Paper No. 174.

[16] JOCANOVIC, M. T., KARANOVIC, V. V., KNEZEVIC, D. M., OROSNJAK, M. D. Diesel fuel filtration problems with modern common rail injection systems. Vojnotehnicki Glasnik. [online]. 2017, 65(4), p. 968-993. ISSN 0042-8469, eISSN 2217-4753. Available from: https://doi.org/10.5937/vojtehg65-11577

[17] RAJAK, U., NASHINE, P., VERMA, T. N., PUGAZHENDHI, A. Performance, combustion and emission analysis of microalgae Spirulina in a common rail direct injection diesel engine. Fuel. [online]. 2019, 255, 115855. ISSN 0016-2361. Available from: https://doi.org/10.1016/j.fuel.2019.115855

[18] SAPIO, F., PIANO, A., MILLO, F., PESCE, F. C. Digital shaping and optimization of fuel injection pattern for a common rail automotive diesel engine through numerical simulation. SAE Technical Paper [online], 2017, 2017-24-0025. ISSN 0148-7191, eISSN 2688-3627. Available from: https://doi.org/10.4271/2017-24-0025

[19] TZANETAKIS, T., VOICE, A. K., TRAVER, M. L. Durability study of a high-pressure common-rail fuel injection system using lubricity additive-dosed gasoline-like fuel. SAE International Journal of Fuels and Lubricants [online]. 2018, 11(4), p. 319-336. ISSN 2641-9637, eISSN 2641-9645. Available from: https://doi.org/10.4271/2019-01-0263

[20] ABRAMEK, K. F., STOECK, T., OSIPOWICZ, T. Statistical evaluation of the corrosive wear of fuel injector elements used in common rail systems. Strojniski vestnik - Journal of Mechanical Engineering [online]. 2015, 61(2), p. 91-98. ISSN 0039-2480, eISSN 2536-2948. Available from: https://doi.org/10.5545/sv-jme.2014.1687

[21] LAZAREV, V. E., WLOKA, J. A., WACHTMEISTER, G. A Method for the estimation of the service life of a precision guiding interface "Needle-Nozzle Body" of a common-rail-injector for high rail pressures. SAE Technical Paper [online], 2011, 2011-01-2020. ISSN 0148-7191, eISSN 2688-3627. Available from: https://doi.org/10.4271/2011-01-2020

[22] RICCO, M., DE MATTHAEIS, S., OLABI, A. G. Simulation of the magnetic properties for common rail electro-injector. Journal of Materials Processing Technology. [online]. 2004, 155, p. 1611-1615. ISSN 0924-0136. Available from: https://doi.org/10.1016/j.jmatprotec.2004.04.343

[23] KURCZYNSKI, D., LAGOWSKI, P. Performance indices of a common rail-system CI engine powered by diesel oil and biofuel blends. Journal of the Energy Institute [online]. 2019, 92(6), p. 1897-1913. ISSN 1743-9671. Available from: https://doi.org/10.1016/j.joei.2018.11.004

[24] ZHAO, J., YUE, P., GREKHOV, L., MA, X. Hold current effects on the power losses of high-speed solenoid valve for common-rail injector. Applied Thermal Engineering [online]. 2018, 128, p. 1579-1587. ISSN 1359-4311. Available from: https://doi.org/10.1016/j.applthermaleng.2017.09.123

[25] GREKHOV, L. V., DENISOV, A. A., STARKOV, E. E. Requirements justification for fuel injection system, energy-efficient low-emission diesel engines. VSTU News. 2014, 6(18), p. 7-11. ISBN 978-5-9948-1574-8.

[26] IVASHCHENKO, N. A., GREKHOV, L. B., TSZIANKHUEI, CH. Method of calculating the quick-operating drive of the control valve of the fuel supply equipment. Internal Combustion Engines (All-Ukrainian Scientific and Technical Journal). 2012, 1, p. 65-69. ISSN 0419-8719.

[27] CHIATTI, G., CHIAVOLA, O., PALMIERI, F. Phenomenological approach for common rail diesel engine emission and performance prediction. SAE Technical Paper [online], 2010, 2010-01-0874. ISSN 0148-7191, eISSN 2688-3627. Available from: https://doi.org/10.4271/2010-01-0874

[28] COPPO, M., DONGIOVANNI, C., NEGRI, C. A linear optical sensor for measuring needle displacement in common-rail diesel injectors. Sensors and Actuators A: Physical [online]. 2007, 134(2), p. 366-373. ISSN 0924-4247. Available from: https://doi.org/10.1016/j.sna.2006.05.038

[29] GREKHOV, L. V., DRAGAN, Y. E. E., DENISOV, A. A., STARKOV, E. Injection rate shaping with possibilities of conventional design common rail system. International Journal of Applied Engineering Research. 2015, 10(5), p. 3979-3986. ISSN 0973-4562.

[30] GREKHOV, L., MAHKAMOV, K., KULESHOV, A. Optimization of mixture formation and combustion in two-stroke OP engine using innovative diesel spray combustion model and fuel system simulation software. SAE Technical Paper [online], 2015, 2015-01-1859. ISSN 0148-7191, eISSN 2688-3627. Available from: https://doi.org/10.4271/2015-01-1859

[31] KULESHOV, A., GREKHOV, L. Multidimensional optimization of DI diesel engine process using multi-zone fuel spray combustion model and detailed chemistry NOx formation model. SAE Technical Paper [online], 2013, 2013-01-0882. ISSN 0148-7191, eISSN 2688-3627. Available from: https://doi.org/10.4271/2013-01-0882 
[32] LAU, K., JUNK, R., KLINGBEIL, S., SCHUUMANN, U., STREIBEL, T. Analysis of internal common rail injector deposits via thermo desorption photon ionization time of flight mass spectrometry. Energy and Fuels [online]. 2015, 29(9), p. 5625-5632. ISSN 0887-0624, eISSN 1520-5029. Available from: https://doi.org/10.1021/acs.energyfuels.5b01114

[33] SHATROV, M. G., GOLUBKOV, L. N., DUNIN, A. U., YAKOVENKO, A. L., DUSHKIN, P. V. Experimental research of hydrodynamic effects in common rail fuel system in case of multiple injection. International Journal of Applied Engineering Research. 2016, 11(10), p. 6949-6953. ISSN 0973-4562.

[34] WROBLEWSKI, A. Modeling of hydrodynamic processes in diesel injector nozzle. Mechanics [online]. 2019, 25(2), p. 128-133. ISSN 1392-1207, eISSN 2029-6983. Available from: https://doi.org/10.5755/j01.mech.25.2.19326 